\title{
Eliminating transportation waste using the transportation value stream map
}

\author{
Mihaela Cornelia POPESCU \\ The Bucharest University of Economic Studies, Bucharest, Romania; Doctoral School of \\ Business Administration \\ mihaela.popescu@fabiz.ase.ro
}

\begin{abstract}
The paper reveals how lean instruments and metrics applied in transportation translates the importance of logistic visibility and shared information between shippers, brokers, carriers and customers along the supply chain management. Recreating a new transportation network emphasizes the idea of discovering practical strategies and actions of reducing muda in terms of efficiency and costs. Transportation cost has to be focused on frequency of trips, shipping size, distance travelled, guide routes and deficient rates. One of the objectives of the research was the analysis of the transport efficiency using the Value Stream Mapping as an important lean tool used by many practitioners to identify sources of waste and to propose alternatives of improvement. As a first conclusion of the study, transportation cannot be analyzed like a distinct part of the supply chain, therefore, VSM had to be considered, structured and visualized as linked processes of wasteful activities that need to be measured and improved. The transportation network design reflects the geographic distribution conditions, the frequency and size of the orders, the gaps between the in-transit activities and non-intransit activities. Waste identification research was focused on elaboration of Transportation Visual Map starting with main activities such as: shipment loading, transporting goods to destination, unloading processes, and transportation back to the base and handling the paperwork. MOVE Measure was the new metrics that determined the transportation efficiency in terms of availability, performance and quality, all the factors being expressed in percentage. The results of the research showed the importance of using the VSM tool in transforming the transportation segment of the supply chain from a non-value- adding activity into an optimized value- adding process.
\end{abstract}

Keywords: value stream map, transportation cost, transport efficiency, move measure, valueadding- activity.

\section{Introduction}

The last reports from Census of Manufacturers reveal that $70 \%$ of the production companies in the USA have already introduced and applied the lean thinking principles, by perceiving the main processes as continuous activities of improvement.

When it comes to lean approach, Womack and Baugh (2009) underline the importance of recognizing and differentiating the non-value activities from the value-added activities, the analysis being made from the customers' perspectives, using the value stream mapping. According to Emiliani (2016) a realistic visual map has to be conceived and framed in order to specify value reviewing the most valuable customers and not from a departmental point of view (such as R\&D). Howell and Ballard (2016) referred value stream map as the "process flow charts" that identify specific actions that conduct immediately to the next one. Basically, VSM depicts the current state of a value stream with all the inefficient activities discovered before all the changes and improvements are being made. Therefore, a complete analysis assumes the idea of framing the future state of a value stream based on change management process including 3 important management activities 
such as problem solving, physical transformation and information management. (Villarreal, 2012).

In opinion of Zaman and Ahsan (2014), Value Stream Mapping is a major tool to focus on processes that need to be transformed from input to valuable output in order to satisfy the customers' needs. Visual Stream Map is the clear flow of material and information in the current state with pin-points of waste that need to create a future improved visual map. Kuhlag (2011) underlines the importance of value stream mapping having great influence on increasing the productivity and reducing the lead time. (Zaman \& Ashan, 2014).

Transportation Value Stream Mapping is an adapted version of VSM used with the main purpose of identifying sources of waste during the transportation operations of all kinds of carriers and freight brokers. TVSM proposed will define the specific types of waste and will measure the overall transportation efficiency using TOVE index and KPIs metrics.

Nakajima (1988) and later on, Simmons, Mason \& Gardner (2004) developed the OVE (overall vehicle effectiveness) measure for manufacturing companies who had their own transportation management system. The measure was adapted and extended by Villarreal (2009) who considered total calendar time as calculation base, instead of loading time for reducing waste related to efficiency factors such as availability, performance and quality.

Villarreal recreated a new version of TVSM starting with the idea of integrating the just-in-time approach of "milk runs", by dividing the main processes in non-in-transit activities and in-transit activities. (Villarreal, 2012)

In order to avoid analysis "paralysis" (Cerasis, 2014), the scholars recommend 3 to 5 KPIs indicators for measuring the overall transport efficiency. Transport metrics that matter the most refer to freight cost per unit shipped, transit time, claims as percentage of the freight cost, the truckload capacity utilized, the volume of dead- head miles travelled, driver brakes, fines due to not respecting the federal regulations, extra miles travelled, ontime pick-ups and deliveries, fuel efficiency. The metrics obtained due to application of TVSM will be centralized, integrated and distributed as the main factors of product like availability, performance and quality. The level of TOVE index will be obtained as the multiplied results of each factor.

The paper presents the most important materials and research's results in applying the lean thinking instruments in transportation field and how the TVSM is being used by freight carrier companies in order to depict sources of waste that need to be eliminated. The last part provides relevant discoveries, conclusions and proposed solutions for increasing the efficiency of transportation solution in terms of vehicle optimization, improved road time and reduced costs.

\section{Literature review}

The manufacturing industry went through big changes in the last decade due to globalization, a continuous expansion of the international trade, along with the high level use of computer technology programs. Transportation and distribution industry represents $20-30 \%$ of the supply chain cost; therefore, the efficiency of transportation solution has a huge impact over companies' performances. (Garza-Reyes, Forero, Kumar, Villarreal, Cedillo- Campos\& Roch- Lona, 2017) 
The evolution and trends for transportation industry report and increase in volume of transported goods which it will conduct automatically to higher estimated transportation rates of $9-10 \%$ by 2018 . It is also estimated a shortage with about 55,000 drivers in the USA, due to introducing the electronic logbook; however, the carriers able to attract team drivers will gain real competitive advantage on the effort of contracting dedicated freight with 3PL or manufacturing companies. (Cerasis, 2017)

PICBE | 795

Lean management in transportation must be visualized in the new context of intensive trade activities, imposing companies an enlargement or renewal of the trucks' fleet with the setbacks points of heavier truck regulations and scarcity of the drivers.

A lean integrated solution requires a lot of planning and control throughout the process of managing different transportation modes, developing multiple brokers' contracts, coordinating and dispatching drivers and processing paperwork. In order to succeed, companies are mandatory to have the right planning tools, good knowledge of selecting the right shippers and freight brokers, and the right processes to avoid waste and to manage tight delivery schedules.

The driven principle in lean logistics is visibility in the supply chain management as the top priority for all parties involved in the process of shipping and delivering products and services. The new trend is translated as a continuous improvement of tracking capabilities of the shipment and the importance of sharing information along the supply chain between important factors. (Cerasis, 2017)

Oleghe and Salonitis (2016) consider lean management a set of practices intended to obtain perfect processes through continuous elimination of waste and permanent improvement. LM becomes valid and useful when tools such as Just-in Time, TQM, Visual Stream Map or 5S are put into practice. (Oleghe \& Salonitis, 2016)

According to Hazier and Render (2014), eliminating waste means "synchronizing the demand of upstream and downstream" which entitles the large-scale manufacturers to be able to control the production rate and to reorganize the whole transportation management from storing, load planning, shipping and distributing the products by respecting the customers' demand with no waste of inventories. Introducing the RFID (radio frequency identification device) system with its main function of tracking and collecting data automatically about each item produced and shipped, was a huge step in eliminating waste not only at the warehouse management level but also at the transit level, from the moment of leaving the dock to the final delivery. RFID enlarges the visibility of the production and transportation processes at both levels of enterprise and Supply Chain systems. (Heizer \& Render, 2014)

Numerous studies were dedicated to the application of lean thinking tools to Supply Chain (Mohammadust, 2015) and specific research applied in transportation sector was developed by Hines and Taylor (2000) and few years later by Villarreal, though, from a different perspective. Transportation flow and growth were measured starting from the idea of how the waste from manufacturing activities reflects losses and Muda in the transportation operations, future VSM depicting areas of improvement and practical solutions. (Valeria Garza Amaya, 2017).

In the effort of changing the traditional management system to the lean logistics management, large freight brokers and carriers have adopted the latest version of the Transportation Management System, a substitute of Supply Chain System concerning transportation operations and part of an ERP system. The LeanTMS program integrates 
warehouse management with transportation management to a more efficient planning and decision process (using indicators such as transport cost, load time, supply and demand transportation updates, spot quotes, EDI- electronic data integration, predictive analysis), transportation execution (broker or carrier acceptance, electronic logbook tracking), transportation follow-up (load tracking, rerouting, defective driving warning) and measurement (transit time, loading-unloading reports, claims).

Developing and applying the Transportation VSM tool is not an easy task, this statement being backed-up by many reasons. First of all, the transportation industry is composed by a complex of processes, companies and relationships gathered in legal forms of 3PL, 4PL, 5PL companies, freight forwarders, logistic brokers, common and contract carriers having specific roles in the complicated chains of shipping and distribution of products. Another important argument that sustains the difficulty of constructing an objective visual stream map is the interdependency between all parties involved which imply a great amount of waste, hard to be measured and eliminated.

Large manufacturers from different industries or big distribution centers of important retailers have three options when it comes to transportation logistics process: having their own fleet of trucks, trailers and drivers, outsourcing the distribution operations by outsourcing the transportation operations to a third party and using for-hire freight companies or freight logistic brokers based on the companies' needs to cover nondedicated lanes. Usually, there is a combination of all three types of transportation management system, particularly used by most companies from automotive industry.

The complexity of transportation management translates the interdependency between all the actors involved, starting with shippers, manufacturers, continuing with carriers, brokers and customers, each one of them producing a certain amount of waste with implication in overall transport efficiency and in the same time receiving the consequences of other parties' poor management. The attention is concentrated to a common freight carrier whom main activities are focused on bidding and obtaining loads from brokers, assigning loads to drivers, fulfilling the transportation operations, handling the paperwork. Apparently simple tasks, those activities are influenced by the waste accumulated due to the shipper's activity in which there is no use of RFID system or there is a delay in packing and bringing the product to the dock or handling the bill of lading properly by the administrative department. A poor communication system between the shipper and the broker can results to improper loading or an overweight problem, leading to a waste of time, driver frustration, customer claims and possible fines.

The analysis made, started from the main idea of considering transportation a source of waste in the supply chain context. According to Monden (1993), the entire freight transport should be classified as non-adding value activity, and the best situation will be for the manufacturing facility to be the next to the retail points with minimum of transport costs. (Villarreal, 2012)

Previous research reveals five types of waste with major impact during the transportation and distribution services: driver brakes, excess load time, fill loss, speed loss and quality delays, integrated into three main criteria: availability, performance and quality. By multiplying the results of the criteria was obtained the OVE metrics. (Simmons et al, 2004)

The OVE measure proposed by Simmons et al. (2004) was extended by Guan (2003), considering the performance factor as result of route and time efficiencies. The new 
metrics was renamed MOVE being estimated by multiplying the level of route efficiency, time, quality and vehicle utilization rates. (Villarreal, 2012)

Villarreal and his team brought the research to a higher level of improvement by identifying another source of waste for each criterion. The lean's VSM tool was adapted in order to increase the overall efficiency in the transportation operations. The new adapted map was named TVSM (transportation visual map), consisting in micro and macro characteristics of the route and identifying the components of the TOVE index. At the performance level, excess distance time or unscheduled maintenance were discovered to be important sources of waste in terms of time and cost. From the freight carrier's perspective, the TVSM must be constructed taking into account the impact of waste created by its partners over the company's transportation efficiency. The operating level of the NIT activities depends on the reliability of the logistic broker or 3PL Company in the purpose of fast contracting the freight or processing the documents. The present research is motivated by the complexity and the importance of determining or measuring the performance of a freight contract carrier from the USA, with the final purpose of suggesting and putting in practice ideas of improvement and constant increase in efficiency.

\section{Research methodology}

\section{Constructing the TVSM and calculating the TOVE index}

The company operates in Warren, MI, employing around 45 drivers and owner operators, being involved in the automotive industry and having as main customers important manufacturers such as Ford, GM and Toyota. The freight carrier is licensed and authorized to contract freight opportunities through other big carriers, 3PL companies or logistic brokers. Being part of a 3PL system, the logistic department of the company managed to sign contracts with XPO, one of the largest 3PL companies in the USA, and also with other large transportation management companies like FEDEX, Panther II and Ryder. All of these transportation providers use their own fleet but offer load opportunities to other carriers when the demand of the automotive parts increases over the manufacturers' expectations, or there is a shortage in inventory along the Supply Chain of one of the automotive manufacturers mentioned.

The lean methodological approach for establishing the efficiency of the road transportation operations of the studied company starts from the point of dividing the main activities into three categories: load planning and preparation as important non-in transit tasks, fulfilling shipping orders, loading activities, handling paperwork and transportation as moments considered in transit activities, and completing the customers' orders representing by the delivery activities, possible claims and returns as in transit activities as well. Compared to the OEE (overall vehicle effectiveness) measure proposed by Simmons et al (2004), where the metrics refer to availability, performance and quality, TOVE measure takes into consideration the administrative availability metrics as an important source of waste, in need to be identified and measured. (Villarreal, 2009)

In order to frame an objective TVSM and measure the TOVE index, it was necessary to collect data, through direct observation, about the efficiency of the transportation operations of the trucks engaged in fulfilling the contracts with the main transportation providers such Ryder, Panther II and XPO. Garza-Reyes (2017) and Villarreal (2012) present an impressive amount of waste need to be eliminated from the administrative 
processes. However, in the present case, the operating availability components refer to the time associated with the bidding process, the reliability of the rates confirmation, the dispatching operativity and accuracy of the documents. These are considered as non-in transit activities, managed by the logistic department of the carrier. Other operating efficiency activities are related to unloading time, product rejection time and releasing the documents, managed by the customers' administrative department, registered during transportation. The results obtained reflect the availability efficiency regarding the operating processes. The performance efficiency index is calculated starting with waste accumulated during the transportation and refer to the fill loss ( $\%$ of the truck utilization), speed loss (maximum speed reachable compared to the average speed registered) and excess distance travelled. An important quality efficiency indicator is related to the number of delays reported at the shipping and delivery points, compared to the total number of delays reported due to drivers' inefficiency. Quality index resumes the efficiency as the percentage of total number of loads with no claims or rejections, the percentage as number of orders delivered on time and percentage as number of loads with no fines due to not respecting the federal or the state regulations.

The TVSM will be oriented to a clear presentation of the transportation related activities, from the moment when the truck is ready to be assigned to a new load, to analysis of the main processes, in terms of time, operativity and cost, establishing points of loss or waste, calculating the TOVE index in the purpose of finding better solutions finalized with a new proposed visual map.

\section{TVSM for TX-SC round-trip}

The route is a dedicated lane from Laredo, TX to South Court, SC and back with a total of 2750 miles. There are different problems that need to be brought-up to discussion. Starting from the 14 hours journey time, it must be considered as mandatory the $11 \mathrm{~h}$ of driving, at least $1 \mathrm{~h}$ necessary for fueling and other maintenance problems, which remains a maximum $2 \mathrm{~h}$ dedicated to loading and unloading processes. In case of time loss due to loading and unloading problems, the drivers are facing logbook constraints, conducting to rescheduled deliveries or breaking the federal regulations, each case affecting the overall company's performance.

The round trip was available for the whole year and the company managed to complete 40 round-trips out of 60 travels maximum. At maximum of efficiency, a roundtrip can be done using a single driver in 4 days or 1.5 trips per month. The observations were taken from 10 months of activity, motivated by summer shutdown of the main automotive production, the delays recorded and other holiday brakes. Therefore, the maximum attainable round-trips were counted to 60, resulting in a $66 \%$ truck utilization factor, calculating by dividing the miles realized compared to expected miles.

In the stream map shown below (Fig. 1), the time allocated to assigning and dispatching activities, represented $7 \%$ of the total journey time, while the driving time represents $78 \%$ of the total travel time, but from a calendar day, accounts $45 \%$. The loading and unloading time varies from $14 \%$ out of JT (2h), but the time was extended sometimes to $5 \mathrm{~h}$, recording a medium of $3 \mathrm{~h}$ more, in 10 out of the 40 round-trips. Time loss reflected in a negative way the efficiency of the company in terms of performance (reduced number of trips) and cost (fuel, layover fines paid to the drivers). According to the stream map, the 
variation in pick-up and delivery time between $14 \%$ and $35 \%$ is related to inaccuracies in processing the documents, connecting the invoices with the right delivery number, bill of lading or transportation manifest. From the mathematical point of view, it can be said that, $7 \%$ allocated to NIT activities entitles the analyst to consider 93\% efficiency of the logistic department of the carrier. However, from the qualitative point of view, most of the delayed loading and unloading processes were due to lack of double checking the shipper and the customer orders, the ETA (estimated time arrival) of the freight from Mexico, assigning the driver in the precise moment of creating the window time, avoiding future driver constraints. Speed loss is an important factor in decreasing the company's efficiency. The average speed loss registered in all runs was 5 miles/hour, being explained by heavy traffic in states like MS, TX and GA, with many roads in reconstruction. The speed loss had an impact over the number of trips, requiring the driver to comply with federal regulations hours of driving. Dead-head miles loss accounted $21 \%$ of the second day of driving, but overall the waste was reduced to $5.4 \%$ out of the total miles travelled, being taken into consideration in terms of costs (around \$2, 700 in 40 round-trips) and environmental issues.

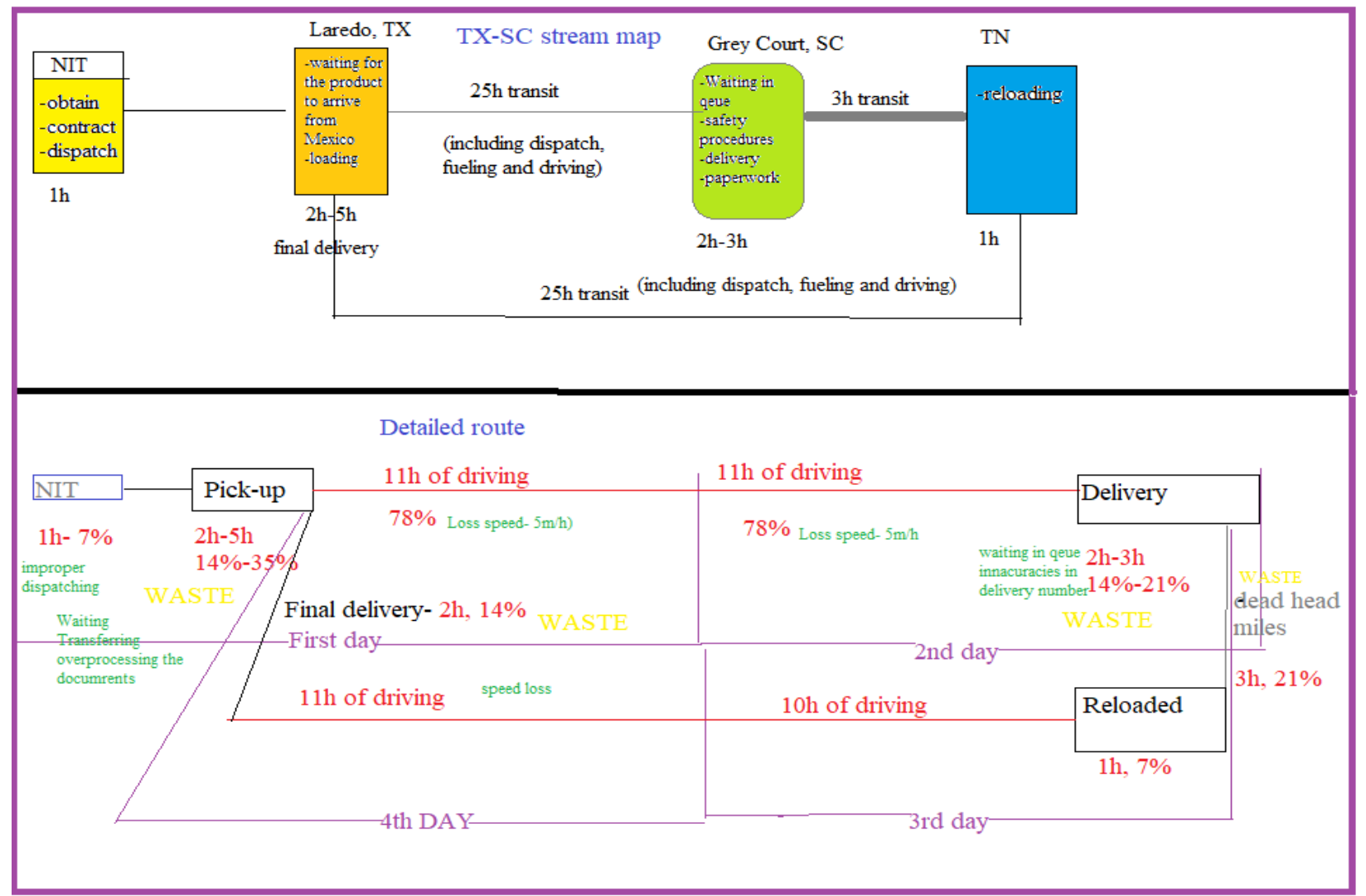

Image 1. Visual stream map for TX-SC round-trip

Source: Adapted from Villarreal (2012).

\section{The analysis of TOVE index}


By reflecting the values of quality, administrative, performance and operational efficiency, the image below shows the level of company' performance. The TOVE index indicates the necessary points of waste, imposing solutions of improvements.

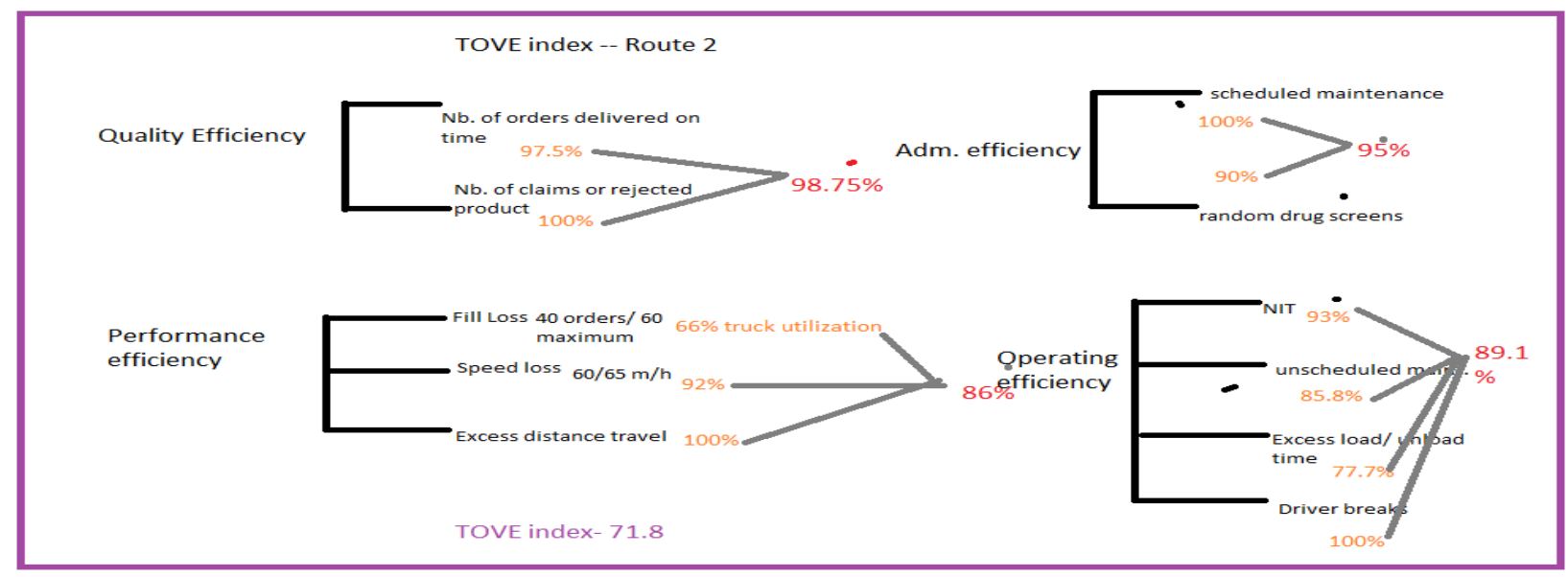

PICBE $\mid 800$

Image 2. TOVE index for TX-SC round-trip

Source: Adapted from Villarreal (2012).

Quality efficiency-98.75\%- From the total number of 40 round-trips only one was registered with delayed delivery due to traffic jams, with a $97.5 \%$ and no rejection product was subject to returns, concluding a very good training and drivers' performance. The delays could be prevented with a constant signaling from the dispatch, rerouting the truck in a proper time.

Performance efficiency- 86\%- The performance low percentage is affected by the $66 \%$ truck utilization factor, with 40 round trips completed out of 60 possible. The explanation relies in two types of waste mention in the value stream map: speed loss and delayed loading and unloading processes. The speed loss indicator of $92 \%$ shows a difference of 5 miles/hour waste between the average speed attainable and the average speed registered. Considering the number of possible 60 round-trips per year, dividing the difference of 3.5 hours between the hours of completing a round trip with $65 \mathrm{~m} / \mathrm{h}$ instead of $60 \mathrm{~m} / \mathrm{h}$, we obtain a number of 4.5 round trips loss, or $7 \%$ waste of truck utilization due to a lower driving speed. Speed loss could be the effect of an old fleet or heavy traffic requiring renewal of the trucks or proper rerouting. Although, no extra miles were driven.

Administrative efficiency- 95\%- The interstate operating authority requires for all the carriers to enroll in a safety and drug screen program, through which the drivers are being tested randomly without prior information, therefore, $10 \%$ loss was recorded due to performing the tests.

Operating efficiency- 89.1\%- The NIT activities reflects the efficiency of the logistic department in terms of fast assignment, contracting and dispatching the drivers, depicting the importance of maintaining the partnerships through reliable behavior and operability. However, the fastness is not a guarantee to qualitative activities with no waste of time, cost and efficiency. In $25 \%$ of documents, inaccuracies were due to mismatches between the shippers' documents and load orders received from the brokers. The unscheduled maintenance factor is $85.8 \%$, after recording two truck breakdowns in 40 round-trips. The operating efficiency factor percentage is mostly affected by the excess loading and unloading time waste of $77.7 \%$. The average loss is 3hours per round trip which perfectly 
reflects a loss of truck utilization with 4 round trips out of 60 possible, exactly $6.6 \%$ travel waste.

\section{Research findings}

From the TVSM presented, it can be depicted several types of non-value activities that affect the overall company's efficiency and level of TOVE index. Although the NIT operations take around 7\% out of total journey time, numerous inaccuracies in processing documents and lack of coordination between the stakeholders was found, decreasing the level of operating efficiency. Mismatches in freight bill numbers or quantity ordered conducted to long hours of loading and unloading time with waste of fuel, driving hours and cost operation. In many cases, the drivers were forced to increase the speed limit during the transit, risking fines and bad federal reports, in order to satisfy the customers' needs of fast delivery, preventing any production delays.

The table below reveals the most important types of waste and non-value activities, registered and monitored during the contracts' rolling time.

Table 1- Non- value-added activities

\begin{tabular}{|l|l|}
\hline WASTE & ACTIVITIES \\
\hline 1.Documents over-processing & $\begin{array}{l}\text {-Inaccuracies of order number, bill of lading, delivery } \\
\text { invoices } \\
\text {-Improper dispatching, lack of information } \\
\text {-Delays in routing and directing the trucks }\end{array}$ \\
\hline 2.Waiting & $\begin{array}{l}\text {-Long hours of loading and unloading } \\
\text {-Waiting in queue }\end{array}$ \\
\hline 3.Resource utilization & $\begin{array}{l}\text { - 66\% truck utilization due to long hours of loading } \\
\text { and unloading }\end{array}$ \\
\hline 4. Speed loss & $\begin{array}{l}\text { - Traffic jams } \\
\text {-Poor rerouting dispatch activity } \\
\text { - No GPS or Macro-point tracking system }\end{array}$ \\
\hline 5. Unscheduled maintenance & - 2 minor repairs in transit \\
\hline 6. Excess miles & - Dead-head miles \\
\hline 7. Returns & - No rejections \\
\hline
\end{tabular}

Source: Author's own processing.

The application of TVSM and TOVE index will entitle the carrier to proceed to a change management process addressed to specific area of improvement such as NIT activities, better coordination and access to shippers' and customers' transportation management systems, faster tracking system, continuous communication with the drivers and high level of monitoring the quality of the fleet.

\section{Conclusions and recommendations}

The study reflects the importance of the relationships between the carrier studied and its most important partners (brokers, customers, 3PL companies), in developing lean transportation operations by applying the lean instruments and avoiding waste and losses.

Constructing a transportation visual map, the logistic operation team can identify the area of improvement and proposes better solutions with positive impact over the company's most important KPIs.

Many transportation experts are using the visual map tool in the main purpose of increasing the efficiency and reducing the distribution costs by relocation the facilities or 
by changing the mode of transport. The present research tries to identify through TVSM the pin-points of transportation waste and to suggest different ideas of improvement.

It is very important for the carrier to make a clear selection of the load opportunities, by choosing shippers who use the RFID barcoding system of monitoring the freight, decreasing the time allocated to loading and processing the documents.

Improving the communication system between the company's drivers and the brokers could be realized by choosing a common IT program like Macro-system through which the load information is updated immediately. This would spare a lot of time and would allow the logistic team to contact the shipper in a time manner in case of improper loading or documentation.

By selecting the brokers who collaborate with big manufacturer companies aligned to the lean philosophy, will decrease the risk of long hours of loading and unloading, due to the fact that most of them function using rigorous schedules of pick-up and deliveries with high level of monitoring the efficiency of those activities.

The dedicated lanes usually require a continuous flow of in-transit activities and any delays could have unpleasant consequences on the manufacturing and distribution processes. Therefore, the good quality of the fleet is a must. The safety manager of the carrier should give more attention to the scheduled maintenance factor by monitoring carefully the tractors and trailers, and in some cases, renewing them being the best solution.

Along with mathematical models of calculating the efficiency of the transportation operations, the TVSM and the TOVE metric offer a better vision of the company's performance overall, depicting sources of waste and loss. Although, the improvements suggested have not been implemented yet, the present paper could be a good source for logistic companies, interested in further application of the lean theory and tools.

\section{References}

Alicke, K. \& Losch, M. (2010). Lean and mean: how does your supply chain shape up? Mckinney\&Company

Benavides-Pena, I., Garza-Amaya, V., Garza-Madero, C. \& Villarreal, B. (2017). Improving On-time delivery eliminating routing waste- a case study. Morocco, International Conference on Industrial Engineering and Operations Management, Apr. 11-13

Brown, A., Amundson \& J., Badurdeen, F. (2014). Sustainable value stream mapping (VSM) indifferent manufacturing system configurations; applications and studies. Journal of Cleaner Production 85, 104-179

Chen, J. C., Cheng, C. H., \& Huang, P. B. (2013). Supply chain management with lean production and RFID application: A case study. Expert Systems with Applications, 40(9), 3389-3397.

Cerasis, (2017). The most impactful Supply Chain Logistics trends in 2017. http.cerasis.com

Cerasis, (2017). How to shift from tactical to strategic logistic\& transportation management to create a competitive advantage. www.cerasis.com

Cortez, H., Daaboul, J., Duigou, J. \& Eynard, B. (2016). Strategic Lean Management: Integration of operational performance indicators for strategic lean management. IFAC, 49(12), 65-70

Garza-Reyes, J.A., Forero, J.S.B., Kumar, V., Villarreal, B., Cedillo- Campos, M.G. \& Roch-Lona, 
Conference on Flexible Automation and Intelligent Manufacturing, FAIM2017, Modena, Italy, 27-30 June 2017, doi:10.1002/brb3.341

Heizer, J. \& Render, B. (2014). Operations Management, Eleventh Edition, Prentice Hall, Upper Saddle River, NJ

Ljungblom, M. (2014). Ethics and Lean Management-a paradox?. International Journal of Quality and Service Sciences, 6(2/3), 191-202

Oleghe, O. \& Salanitis, K. (2016). Variation modeling of lean manufacturing performance using fuzzy logic based quantitative lean index. $48^{\text {th }}$ Conference on Manufacturing System, Elsevier, 8.01.2016, 41, 608-613, doi.org/10.1016

Paunescu, C. \& Acatrinei, C. (2012). Managing maturity in process-based improvement organization: a perspective of the Romanian Company. Journal of Business Economics and Management, 13 (2), 223-241

Paunescu, C., Pascu, Al. \& Pop, O. (2016). Social enterprise: how does this way of doing business differ from other forms of enterprise? Quality- Access to Success, 17(153), 108-110

Simmons, D., Mason, R. \& Gardner, B. (2004). Overall vehicle effectiveness. International Journal of Logistics: Research and Applications, 7, (2), 119-135

Sisson, J. \& Elshennawy, A. (2015). Achieving success with lean- an analysis of key factors in lean transformation at Toyota and beyond. International Journal of Lean Six Sigma, 5, (2), 122-148

Stich, V. \& Groten, M. (2015). Design and simulation of a logistic distribution network applying the Viable System Mode (VSM). Elsevier, Procedia Manufacturing, 6, 534541

Villarreal, B. (2012). The transportation value stream map (TVSM). European Journal of Industrial Engineering, 6(2), 216-233.

Zaman, K.A.U. \& Ahsan, A.M.M. (2014). Lean Supply Chain Performance measurement. International Journal of Productivity and Performance Management, 63, (5), 588612 